\title{
Comparison of hand grip strength and upper limb pressure pain threshold between older adults with or without non- specific shoulder pain
}

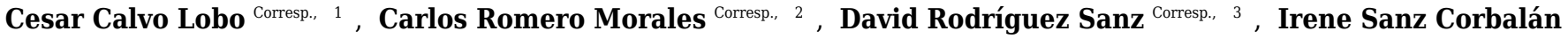

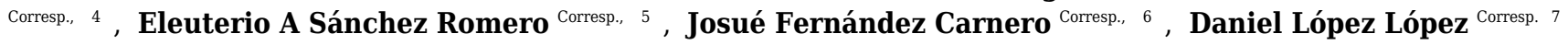 \\ 1 Physiotherapy Department, Motion in Brains Research Group, Instituto de Neurociencias y Ciencias del Movimiento, Centro Superior de Estudios \\ Universitarios La Salle, Universidad Autónoma de Madrid, Madrid, Spain \\ 2 Physical Therapy \& Health Sciences Research Group, Physiotherapy Department, Faculty of Health, Exercise and Sport, European University, Madrid, \\ Spain \\ 3 Physical Therapy \& Health Sciences Research Group; Physiotherapy Department, Faculty of Health, Exercise and Sport, European University, Madrid, \\ Spain \\ ${ }^{4}$ School of Nursing, Physiotherapy and Podiatry, Universidad Complutense de Madrid, Madrid, Spain \\ 5 Faculty of Health Sciences, Universidad Rey Juan Carlos, Madrid, Madrid, Spain \\ 6 Faculty of Health Sciences, Universidad Rey Juan Carlos, Madrid, Spain \\ 7 Research, Health and Podiatry Unit, Department of Health Sciences. Faculty of Nursing and Podiatry, Universidade da Coruña, Ferrol, A Coruña, Spain \\ Corresponding Authors: Cesar Calvo Lobo, Carlos Romero Morales, David Rodríguez Sanz, Irene Sanz Corbalán, Eleuterio A Sánchez Romero, Josué \\ Fernández Carnero, Daniel López López \\ Email address: cecalvo19@hotmail.com, carlosmorales92@hotmail.com, davidrodriguezsanz@gmail.com, iresanzcorbalan@gmail.com, \\ elusanchezromero@gmail.com, josuefernandezcarnero@gmail.com, daniellopez@udc.es
}

Background: There is a high prevalence of non-specific shoulder pain associated with upper limb functional limitations in older adults. The purpose of this study was to determine the minimal clinically important differences (MCID) of grip strength and pressure pain threshold (PPT) in the upper limb between older adults with or without nonspecific shoulder pain. Methods: A case-control study was carried out following the Strengthening the Reporting of Observational Studies in Epidemiology (STROBE) criteria. A sample of 132 shoulders (mean \pm SD years) with $(n=66 ; 76.04 \pm 7.58)$ and without $(n=66$; $75.05 \pm 6.26$ ) non-specific pain were recruited. The grip strength and PPT of the anterior deltoid and extensor carpi radialis brevis (ECRB) muscles were assessed. Results: There were statistically significant differences (mean \pm SD; $P$-value) for anterior deltoid PPT $\left(2.51 \pm 0.69\right.$ vs $\left.3.68 \pm 0.65, \mathrm{~kg} / \mathrm{cm}^{2} ; P<.001\right)$, ECRB PPT $\left(2.20 \pm 0.60\right.$ vs $3.35 \pm 0.38 \mathrm{~kg} / \mathrm{cm}^{2}$; $P<.001)$ and grip strength $(20.78 \pm 10.94$ vs $24.63 \pm 9.38 \mathrm{~kg} ; P=.032)$ between shoulders with and without non-specific pain, respectively. Discussion: The MCID of $1.17 \mathrm{~kg} / \mathrm{cm}^{2}$, $1.15 \mathrm{~kg} / \mathrm{cm}^{2}$ and $3.84 \mathrm{~kg}$ were proposed for anterior deltoid PPT, ECRB PPT and grip strength, respectively, to assess the upper limb of older adults with non-specific shoulder pain after treatment. In addition, univariate and multivariate (linear regression and regression trees) analyses may be used to consider age distribution, sex, pain intensity, grip strength and PPT in older adults including clinical and epidemiological studies with 
non-specific shoulder pain. 
1 Article type: Scientific/Clinical Research Reports

2 Word count for abstract: 223 words.

3 Word count for manuscript: 3344 words.

4

\section{Comparison of hand grip strength and upper limb pressure pain threshold between older} adults with or without non-specific shoulder pain.

César Calvo Lobo, PT, MSc, PhDa; Carlos Romero Morales, PT, MSc, PhD ${ }^{\text {b }}$, David Rodríguez

Sanz, PT, DP, MSc, PhDc; Irene Sanz Corbalán, DP, MSc, PhD ${ }^{d}$; Eleuterio Sánchez Romero, PT, $\mathrm{MSc}^{\mathrm{e}}$; Josué Fernández Carnero, PT, MSc, PhD ${ }^{\mathrm{f}}$; Daniel López López, DP, BSc, MSc, PhD․

aPhysiotherapy Department, Motion in Brains Research Group, Instituto de Neurociencias y Ciencias del Movimiento, Centro Superior de Estudios Universitarios La Salle, Universidad Autónoma de Madrid, Madrid, Spain. E-mail: cecalvo19@hotmail.com

bPhysical Therapy \& Health Sciences Research Group, Physiotherapy Department, Faculty of Health, Exercise and Sport, European University of Madrid, Villaviciosa de Odón, Madrid, Spain. E-mail: carlos.romero@universidadeuropea.es 'Physical Therapy \& Health Sciences Research Group, Faculty of Health, Exercise and Sport, European University of Madrid, Villaviciosa de Odón, Madrid, Spain. Email: davidrodriguezsanz@gmail.com 
22

23

24

25

26

27

28

29

30

31

32

33

34

35

36

37

38

39

40

dSchool of Nursing, Physiotherapy and Podiatry, Universidad Complutense de Madrid, Spain. E-mail: iresanzcorbalan@gmail.com

eFaculty of Health Sciences, Universidad Rey Juan Carlos, Alcorcón, Madrid, Spain.

E-mail: elusanchezromero@gmail.com

fFaculty of Health Sciences, Universidad Rey Juan Carlos, Alcorcón, Madrid, Spdain.E-mail: josue.fernandez@urjc.es

gResearch, Health and Podiatry Unit, Department of Health Sciences. Faculty of Nursing and Podiatry. Universidade da Coruña, Spain. E-mail: daniellopez@udc.es

Address all correspondence to: César Calvo Lobo (cecalvo19@hotmail.com); Carlos Romero Morales (carlos.romero@universidadeuropea.es); $\quad$ David $\quad$ Rodríguez $\quad$ Sanz (davidrodriguezsanz@gmail.com); Irene Sanz Corbalán (iresanzcorbalan@gmail.com); Eleuterio Sánchez Romero (elusanchezromero@gmail.com); Josué Fernández Carnero (josuefernandezcarnero@gmail.com); Daniel López López (daniellopez@udc.es).

Statement of Institutional Review Board approval of the study protocol: The study was approved by the Clinical Intervention Ethics Committee of the General Hospital from Segovia (10/2013). All participants gave written informed consent before data collection began. 

with

\section{ABSTRACT}

Background: There is a high prevalence of non-specific shoulder pain associated with upper limb functional limitations in older adults. The purpose of this study was to determine the minimal clinically important differences (MCID) of grip strength and pressure pain threshold (PPT) in the upper limb between older adults with or without non-specific shoulder pain.

Methods: A case-control study was carried out following the Strengthening the Reporting of Observational Studies in Epidemiology (STROBE) criteria. A sample of 132 shoulders (mean \pm SD years) with $(n=66 ; 76.04 \pm 7.58)$ and without $(n=66 ; 75.05 \pm 6.26)$ non-specific pain were recruited. The grip strength and PPT of the anterior deltoid and extensor carpi radialis brevis (ECRB) muscles were assessed.

Results: There were statistically significant differences (mean $\pm \mathrm{SD} ; P$-value) for anterior deltoid PPT $\left(2.51 \pm 0.69\right.$ vs $\left.3.68 \pm 0.65, \mathrm{~kg} / \mathrm{cm}^{2} ; P<.001\right)$, ECRB PPT $\left(2.20 \pm 0.60\right.$ vs $3.35 \pm 0.38 \mathrm{~kg} / \mathrm{cm}^{2}$; $P<.001)$ and grip strength $(20.78 \pm 10.94$ vs $24.63 \pm 9.38 \mathrm{~kg} ; P=.032)$ between shoulders with and without non-specific pain, respectively.

Discussion: The MCID of $1.17 \mathrm{~kg} / \mathrm{cm}^{2}, 1.15 \mathrm{~kg} / \mathrm{cm}^{2}$ and $3.84 \mathrm{~kg}$ were proposed for anterior deltoid PPT, ECRB PPT and grip strength, respectively, to assess the upper limb of older adults with non-specific shoulder pain after treatment. In addition, univariate and multivariate (linear regression and regression trees) analyses may be used to consider age distribution, sex, pain intensity, grip strength and PPT in older adults including clinical and epidemiological studies non-specific shoulder pain. 


\section{INTRODUCTION}

The aging population has a high prevalence of non-specific shoulder pain $(31 \%$ with severe pain intensity) and associated functional limitations (36\% with greater difficulty performing daily tasks associated with reduced internal rotation). This can have a considerable impact on public health. In addition, $41 \%$ of these subjects present with bilateral shoulder pain. This condition may be frequently overlooked and consequently undertreated. ${ }^{1}$

Radiological findings are frequently not be correlated with shoulder pain in older adults.

The cost of imaging shoulders in the elderly-especially magnetic resonance imaging-is significant, and the relevance of the findings is questionable. ${ }^{2}$ New treatments strategies for older adults with symptomatic shoulders are necessary. ${ }^{1}$ Therefore, non-specific shoulder pain is associated with myofascial pain syndrome (MPS), and treatment can reduce pain intensity, increase pressure pain threshold (PPT) and modify grip strength in the upper limbs of older adults. ${ }^{3,4}$

Furthermore, the MPS may be defined as a set of sensitive, motor or autonomic signs and symptoms originated by hyperirritable spots in a muscle taut band-these are myofascial trigger points (MTrPs). ${ }^{5}$ Active MTrPs produce spontaneous and recognized pain while latent MTrPs generate local or referred pain after stimulation. ${ }^{6,7}$ Indeed, the presence of latent MTrPs in the upper limb may influence the peripheral and central sensitization process and alter the strength and PPT in the upper limb of patients with shoulder pain. ${ }^{3,4,8-10}$ Nevertheless, the relationship between shoulder pain and PPT in the upper limb and grip strength should be more widely studied during aging.

On one hand, the aging process generates a non-statistically significant reduction in the PPT of the upper extremities across different age ranges. ${ }^{11}$ Indeed, Neziri et al. ${ }^{12}$ showed that 
86 age, sex, and/or the interaction of age with sex may affect the pressure pain measures.

87 Furthermore, women are more sensitive to PPT than men. Despite this, the influence of sex

88 reduces with age.

89 Lautenbacher et al. ${ }^{13}$ showed that PPT temporal summation may not be influenced by age.

90 The low PPT perception in older adults shows that deep tissue (muscle) nociception may be less

91 influenced by age than superficial tissue (skin) nociception. In conclusion, reference values need

92 to be determined by body region, gender and age increases. ${ }^{12}$

93 On the other hand, an age-related grip strength reduction is shown in the elderly, although 94 this reduction does not reach a statistical significant difference by aged distribution in this 95 population. ${ }^{11}$ Moreover, Abizanda et al. ${ }^{14}$ reported that the grip strength values were almost 96 double in men than in women older adults. Bohannon ${ }^{15}$ and Norman et al. ${ }^{16}$ showed that low grip 97 strength may be associated with increases in premature mortality, disability, risk of 98 complications, length of stay after hospitalization or surgery, and nutritional alterations in older 99 adults. Daily pain is common and is associated reduced grip strength in the elderly. ${ }^{17}$

Grip strength and PPT in the satellite latent MTrPs of the anterior deltoid and extensor 101 carpi radialis brevis (ECRB) muscles were assessed in the treatment of key active MTrPs in the infraspinatus muscle in older adults with non-specific shoulder pain. The treatment of the latent MTrP associated with the key active MTrP of the infraspinatus muscle improves pain intensity and increases the PPT of the satellite latent MTrPs located in the referred pain area over the short term. ${ }^{3,4}$

To date, the minimum clinical important differences (MCID) of the grip strength and PPT 107 in the upper limb have not been established in this population. The aim of this study was to 
108 evaluate the MCID of the grip strength and PPT in the upper limbs between older adults with or

109 without non-specific shoulder pain.

110

111

\section{MATERIAL \& METHODS}

112

113

114

115

116

117

118

119

120

121

122

123

124

125

126

127

128

129

130

\subsection{Design}

A case-control study was carried out from October 2013 to March 2016 following the Strengthening the Reporting of Observational Studies in Epidemiology (STROBE) statement and checklist. ${ }^{18}$ Previously, the study was approved by the clinical research ethics committee of the general hospital from the health area. All subjects signed an informed consent form before their inclusion in the study. Furthermore, the Helsinki Declaration and ethical standards in human experimentation were followed.

\subsection{Participants}

A sample of 132 shoulders (mean \pm SD years) with $(n=66 ; 76.04 \pm 7.58)$ and without $(n=66$; $75.05 \pm 6.26$ years) non-specific pain were recruited from a care center and their homes.

The inclusion criteria were unilateral (for case group) or bilateral (for control group) shoulders from subjects aged 65 and over with or without non-specific shoulder pain. At least 1 latent MTrP in the anterior deltoid and 1 latent MTrP in the ECRB were required for each upper limb to justify their PPT and grip strength assessments. For the case group, both latent MTrPs were located ipsilateral to the painful shoulder. For the control group, these latent MTrPs were situated bilateral in both non-painful shoulders. Shoulder pain was considered if there was pain at rest and mainly located in the glenohumeral joint between the acromion, the insertion of the deltoid muscle, and the lateral region of the scapula. ${ }^{3,4}$ Non-specific shoulder pain was considered if a previous diagnosis was not present in the medical record considering structural, 
131 neurological, visceral or red flag conditions. ${ }^{19}$ A latent MTrP was diagnosed if there were 132 palpable tender nodules in a taut band without the patient's local or referred pain recognition. If

133 there was more than 1 latent MTrP in the same muscle, then the MTrP most hyperalgesic to 134 palpation was selected as the one that generated the highest pain intensity in the Numeric Rating 135 Scale (NRS) under the same pressure. ${ }^{3,4}$ The convention for PPT assessment in musculoskeletal 136 conditions is the use of a designated site rather than the most painful MTrP. ${ }^{10}$ However, we 137 prioritized the most hyperalgesic latent MTrPs due to their relationship with the PPT reduction 138 secondary to peripheral and central sensitization as well as strength modifications in the upper $139 \operatorname{limb} .^{3,4,8,9}$,

The exclusion criteria were prior diagnoses or treatments in the medical record for myopathy, neuropathy, cognitive impairments, joint conditions (cervical, rotator-cuff or glenohumeral regions), surgeries (upper-limb or cervical regions), physiotherapy treatment

143 (within the previous 6 months), corticoid injections (within the previous 1 year), analgesic or 144 anti-inflammatory medication (within the previous 1 week). ${ }^{3,4}$

\subsection{Outcome measures}

A physical therapist with the necessary specialization and experience and good interexaminer reproducibility $(\kappa=0.63)$ in the MTrPs clinical evaluation according to Myburg et $a l .,{ }^{20}$ carried out all of the assessments. Socio-demographic (age and sex), pain intensity, anterior deltoid, ECRB PPT, and grip strength were measured. Pain intensity ipsilateral to the painful shoulder was only assessed in the case group using the NRS, which is recommended for a reliable and valid use in older adults. ${ }^{21}$

\subsubsection{Primary outcome}

PPT was assessed from 0 to $10 \mathrm{~kg} / \mathrm{cm}^{2}$ with a mechanical algometer (FDK/FDN, Wagner 
154 Instruments, Greenwich, CT). This is reliable, reproducible and sensitive for latent MTrPs

155 evaluation in older adults' upper limbs. ${ }^{11-13,22-24}$ The most hyperalgesic latent MTrP in the

156 anterior deltoid and the most hyperalgesic latent MTrP in the ECRB ipsilateral to the painful

157 shoulder (for the case group) or bilateral for the non-painful shoulders (for the control group)

158 were assessed. The procedure (mean of 3 repeated measurements with a $30-60$ seconds interval)

159 and position (supine decubitus with the forearm on the abdomen) were followed according to 160 prior studies. ${ }^{3,4}$

161 2.3.2 Secondary outcome:

162 The maximum grip strength was performed from 0 to $90 \mathrm{~kg}$ with a hydraulic hand

163 dynamometer (JAMAR, Sammons Preston Rolyan, Sammons Court Bolingbrook, IL). This is a 164 valid, reproducible and reliable tool in older adults. ${ }^{14-16}$ Coinciding with the PPT assessment, the 165 painful side for the case group and both upper limbs for the control group were assessed by grip 166 strength. A single assessment (5-10 seconds) used the elbow flexed at $90^{\circ}$ with neutral pronation 167 or supination as well as a sitting position. ${ }^{3,4,14}$

\section{$168 \quad 2.4$ Intraexaminer reliability}

An additional intraexaminer reliability study for the latent MTrP localization procedure coinciding with skin marks was carried out in the upper limb of 42 older adults. The most hyperalgesic latent MTrP was selected at 2 different moments with an interval of at least 1 hour using the same position described for the PPT assessment. Upon the first assessment, the skin was previously marked at the location of the most hyperalgesic latent $\mathrm{MTrP}$ in each muscle. The second assessment used the prior marks that coincided with the displaced skin with each one of

175 the most hyperalgesic latent MTrPs. For the anterior deltoid, the distance $(\mathrm{cm})$ from the most 176 hyperalgesic latent MTrP to the lateral angle of the acromion was performed. For the ECRB, the 
177 distance from the most hyperalgesic latent MTrP to the lateral epicondyle of the elbow was

178 measured. The reason that the previous skin marks were used was because they facilitate a

179 procedure with better intraexaminer reliability for future evaluations during treatments. ${ }^{3,4}$

\section{$180 \quad 2.5$ Data analysis}

SPSS version 22.0 (IBM SPSS Statistics for Windows; Armonk, NY: IBM Corp) and $\alpha$

182

183

184

error of 0.05 (95\% confidence interval) and a desired power of $80 \%$ ( $\beta$ error of 0.2$)$ was used for statistical analysis. The Shapiro Wilk test and the visual distribution did not show large normality deviations. Parametric analysis was used because of this and the large sample size.

Afterwards, a comparison of both the sociodemographic data and the main outcomes was performed between case and control groups. For case and control groups and sex, comparisons used Fisher's exact test. Age was divided into three intervals to permit a similar number of shoulders in each group (from 65 to 70 , from 71 to 80 , and more than 80 [81-97.2] years); Pearson's Chi-square test compared between the case and control groups. Furthermore, Student's t-test for independent samples was used for age and outcomes (anterior deltoid and ECRB PPT, and grip strength) and the sex and age group. The minimum clinical differences of the anterior deltoid and ECRB PPT and grip strength were calculated by subtracting the case group from the control group means according to prior studies. ${ }^{25,}{ }^{26}$ Box plots were used to illustrate PPT and grip strength values from the case and control groups.

A univariate correlation analysis using Pearson's $(r)$ coefficient was performed to evaluate the relationship between the anterior deltoid and ECRB PPT as well as the grip strength measurements of the groups. Correlations were interpreted as weak $(0.00-0.40)$, moderate $(0.41-0.69)$, or strong $(0.70-1.00) .{ }^{27}$

In addition, a multivariate predictive analysis used linear regression and regression trees. 
200 Linear regression was performed via a stepwise selection method and the $R^{2}$ coefficient to

201 establish quality adjustments. Sociodemographic data including age, sex (male=0; female=1),

202 and group (control=0; case $=1$ ) as well as the pain intensity were used as independent variables.

203 The anterior deltoid and ECRB PPT and grip strength were dependent variables.

204 Finally, the intraexaminer reliability for the latent MTrP localization procedure was added

205 according to Bland and Altman. ${ }^{28}$ First, the normality, descriptive analyses and repeated-

206 measures ANOVA were calculated. The intraclass correlation coefficient (ICC) used a two-

207 factor model with mixed effects (ICC A) with absolute agreement and a one-factor model with

208 random effects (ICC B). Cronbach's alpha and the standard error of measurement (SEM) were

209 calculated. In addition, the minimum detectable change (MDC) was calculated for 95\%, 90\% and

$21080 \%$ confidence intervals (CI) using the $\sqrt{2} \tilde{\mathrm{A}}-1.96 \tilde{\mathrm{A}}-s w ; \sqrt{2} \tilde{\mathrm{A}}-1.645 \tilde{\mathrm{A}}-s w$ and

$211 \sqrt{2} \tilde{\mathrm{A}}-1.28 \tilde{\mathrm{A}}-S w$ equations, respectively. The heteroscedasticity was performed by the Kendall

212 tau_b $(\tau \mathrm{B})$ coefficient to validate this method. Bland and Altman graphs were prepared including

213 the agreement limits and the linear regression analysis between the means and the differences

214 (dependent variable) of the measurements. ${ }^{28,29}$

215

\section{RESULTS}

217 The sex and age distribution were homogeneous between case and control groups (Table

218 1). There were statistically significant differences (mean $\pm \mathrm{SD} ; P$-value) for anterior deltoid PPT

$219\left(2.51 \pm 0.69\right.$ vs $\left.3.68 \pm 0.65, \mathrm{~kg} / \mathrm{cm}^{2} ; P<.001\right)$, ECRB PPT $\left(2.20 \pm 0.60\right.$ vs $\left.3.35 \pm 0.38 \mathrm{~kg} / \mathrm{cm}^{2} ; P<.001\right)$

220 and grip strength $(20.78 \pm 10.94$ vs $24.63 \pm 9.38 \mathrm{~kg} ; P=.032)$ between shoulders with and without

221 non-specific pain, respectively. The MCID of $1.17 \mathrm{~kg} / \mathrm{cm}^{2}, 1.15 \mathrm{~kg} / \mathrm{cm}^{2}$ and $3.84 \mathrm{~kg}$ were 
222 proposed for anterior deltoid PPT, ECRB PPT and grip strength, respectively, to treat older

223 adults with non-specific shoulder pain (Figures 1-3).

224 According to the statistically significant differences $(P<.01)$ of the univariate correlation

225 analysis (Table 2$)$, there was a positive correlation from strong $(r=0.806)$ to moderate $(r=$ 2260.590 to 0.677 ) between the anterior deltoid and ECRB PPT. For grip strength of the groups, 227 there was a moderate or weak correlation with the age $(r=-0.327$ to -0.488$)$, anterior deltoid $(r=$ 2280.315 to 0.372 ) and ECRB ( $r=0.303$ to 0.442 ) PPT. The pain intensity did not present any 229 statistically significant difference $(P>.05)$.

The linear regression model (Table 3) showed significant differences $(P<.05)$, and the model $R^{2}$ varied from 0.012 to 0.565 . In addition, the regression trees (Figure 4) established 3-4 statistically significant nodes $(P<.05)$.

Finally, the MTrP localization procedure showed high intraexaminer reliability after one hour of assessment (Table 4). In the anterior deltoid muscle, the most hyperalgesic latent $\mathrm{MTrP}$ was localized $7.07 \pm 1.13(4.55-9.85) \mathrm{cm}$ to the lateral angle of the acromion. In the ECRB muscle, the most hyperalgesic latent MTrP was $6.06 \pm 0.82(4.75-7.88) \mathrm{cm}$ from the lateral epicondyle. A satisfactory randomness within the limits of agreement was seen in the BlandAltman plots (Figure 5).

\section{DISCUSSION}

The proposed MCID for the grip strength, anterior deltoid and ECRB PPT established the presence of statistically significant differences, some interventions did not reach the MCID for 
244 PPT and grip strength in this condition and population. ${ }^{3,4}$

245 Clinically, the findings of this study support the usefulness of the upper limb PPT and grip 246 strength assessments in older adults with non-specific shoulder pain. Nevertheless, some aspects 247 should be considered in these evaluations. First, the latent MTrP PPT of the ECRB presented a 248 larger difference percentage $(34.32 \%)$ than the anterior deltoid $(31.79 \%)$ in painful shoulders 249 with respect to non-painful shoulders. Second, the PPT and grip strength are influenced by the 250 presence of shoulder pain and sex. Nevertheless, the grip strength may only be modified by the 251 age distribution of older adults. Despite the existence of moderate pain intensity, ${ }^{21}$ neither PPT 252 nor grip strength were influenced by the pain intensity of the shoulders. Finally, this is the first 253 study to show a positive correlation between the PPT and grip strength in non-painful shoulders 254 although there is no statistically significant correlation in the painful shoulders. Further research 255 is needed to investigate this field.

256 The PPT minimal detectable increase was proposed as $0.54 \mathrm{~kg} / \mathrm{cm}^{2}$ according to Koo et $257 a l .{ }^{22}$ While Fisher ${ }^{23}$ determined a critical PPT MCID of $2 \mathrm{~kg} / \mathrm{cm}^{2}$ between a normal control point 258 and MTrPs in the general population, Fernández-Carnero et al. ${ }^{30}$ showed that $2.4 \mathrm{~kg} / \mathrm{cm}^{2}$ was the 259 MCID in subjects with lateral epicondylalgia. The MCID of this study varied from 1.15 to 1.17 $260 \mathrm{~kg} / \mathrm{cm}^{2}$. This lower MCID may be because this research was performed between latent MTrPs of 261 subjects with and without non-specific shoulder pain. In addition, older adults have low PPT 262 perception.$^{12}$ The age-related change in pain-evoked activity may produce a functional reduction 263 of brain areas (contralateral putamen and caudate) related to pain modulatory mechanisms with 264 older age. ${ }^{31}$ Therefore, the MCID should be established for each type of condition, body region, 265 sex and age. ${ }^{11-13}$

266 The grip strength MCID was $3.84 \mathrm{~kg}$ in older adults with non-specific shoulder pain. 
267 Nevertheless, the MCID proposed by Dhara et al. ${ }^{32}$ was higher and varied from 6.08 to $19.08 \mathrm{~kg}$

268 in patients with orthopedic conditions (stroke, arthritis and accidents) in the upper limb. This

269 difference may be secondary to the condition type and the age range from 20 to 40 years. In

270 older adults, the grip strength coincided with the reference values proposed by Abizanda et al. ${ }^{14}$,

271 Bohannon ${ }^{15}$ and Cuesta-Vargas \& Hilgenkamp. ${ }^{33}$ In addition, the standard approach to grip

272 strength measurements was followed. ${ }^{14,34}$

273 In addition, univariate (Table 2) and multivariate (Table 3 and Figure 4) analyses may be

274 considered with respect to age distribution, sex, pain intensity, grip strength and PPT in older

275 adults clinical and epidemiological research with non-specific shoulder pain. The linear

276 regression and regression trees show similar conclusions. Furthermore, the regression trees add

277 some important considerations. First, only gender influences the ECRB PPT in the control group.

278 Second, the age distribution only affects the grip strength assessment in women.

279 A high intraexaminer reliability was seen because the MTrPs localization procedure was

280 carried out coinciding with the most hyperalgesic latent MTrP with prior skin marks to justify

281 the PPT assessment point at two different times. ${ }^{3,4}$ Despite this, the $R^{2}$ coefficient, SEM and

$282 \operatorname{MDC}(\mathrm{CI} 95 \%)$ was lower in the ECRB MTrP $(0.005,0.118 \mathrm{~cm}$ and $0.327 \mathrm{~cm})$ than the anterior

283 deltoid MTrP $(0.056,0.122 \mathrm{~cm}$ and $0.338 \mathrm{~cm})$ location (Table 4 and Figure 5), respectively.

284 Nevertheless, the interexaminer reliability was not performed because all assessments were

285 performed by the same rater with the MPS experience necessary to achieve a good interexaminer

286 agreement in the MTrPs location in relation to shoulder pain according to Myburgh. ${ }^{20}$

287 Several limitations should be considered. Despite the wide variability of methods used to

288 calculate the MCID, ${ }^{35}$ we used a case-control study. ${ }^{25,26}$ Age intervals were not equal by years'

289 distribution in order to permit a similar number of shoulders in each group (Table 1). In healthy 
290 older adults, the neuronal circuits of cognitive inhibition and conscious pain control may overlap

291 and interfere with the PPT assessment. ${ }^{36}$ Sympathetic responses are associated with local and

292 referred hyperalgesia of the MTrPs in subjects with shoulder pain, and this may alter the PPT

293 evaluation. ${ }^{37}$ Moreover, the grip strength reference value t-scores were not considered for 294 determining dynapenia in the elderly. ${ }^{38}$ The grip strength evaluation was not divided into 295 dominant and non-dominant upper limbs to establish the MCID for both sides. This assessment 296 might be disturbed by various comorbid conditions in older adults. ${ }^{14-16,33,34,38}$

297

298

\section{CONCLUSIONS}

The MCID increase of the PPT and grip strength is proposed to assess the upper limb after interventions in older adults with non-specific shoulder pain. In addition, univariate and multivariate (linear regression and regression trees) analyses may be used to consider age 302 distribution, sex, pain intensity, grip strength and PPT in older adult's clinical and 303 epidemiological studies with non-specific shoulder pain. 


\section{REFERENCES}

306

307

308

309

310

311

312

313

314

315

316

317

318

3. Calvo C., Pacheco S., Hita E. (2015). Efficacy of deep dry needling on latent myofascial trigger points in older adults with non-specifi c shoulder pain: a randomized, controlled clinical trial pilot study. Journal of Geriatric Physical Therapy, http://10.1519/JPT.0000000000000048.

4. Calvo-Lobo C., Pacheco-da-Costa S., Martínez-Martínez J., Rodríguez-Sanz D., CuestaÁlvaro P., López-López D. (2016). Dry Needling on the Infraspinatus Latent and Active Myofascial Trigger Points in Older Adults With Nonspecific Shoulder Pain: A Randomized Clinical Trial. Journal of Geriatric Physical Therapy, http://10.1519/JPT.0000000000000079.ç

5. Dommerholt J, Hooks T, Finnegan M, Grieve R. A critical overview of the current myofascial pain literature - March 2016. J Bodyw Mov Ther. 2016;20(2):397-408.

6. Ge HY, Arendt-Nielsen L. 2011. Latent myofascial trigger points. Curr Pain Headache Rep. 2011;15:368-392. 
7. Gerber LH, Sikdar S, Armstrong K, Diao G, Heimur J, Kopecky J, Turo D, Otto P, Gebreab T, Shah J. A systematic comparison between subjects with no pain and pain associated with active myofascial trigger points. $P M \& R$. 2013;5:931-938.

8. Ge HY, Fernández-de-Las-Peñas C, Madeleine P, Arendt-Nielsen L. Topographical mapping and mechanical pain sensitivity of myofascial trigger points in the infraspinatus muscle. Eur J Pain . 2008;12:859-865 .

9. Celik D, Yeldan I. The relationship between latent trigger point and muscle strength in healthy subjects: a double-blind study. J Back Musculoskelet Rehabil. 2011;24:251-256 .

10. Coronado RA, Simon CB, Valencia C, George SZ. Experimental pain responses support peripheral and central sensitization in patients with unilateral shoulder pain. Clin J Pain. 2014;30:143-151.

11. Donat H, Ozcan A, Ozdirenç M, Aksakoğlu G, Aydinoğlu S. Age-related changes in pressure pain threshold, grip strength and touch pressure threshold in upper extremities of older adults. Aging Clin Exp Res. 2005;17:380-384.

12. Neziri AY, Scaramozzino P, Andersen OK, Dickenson AH, Arendt-Nielsen L, Curatolo M. Reference values of mechanical and thermal pain tests in a pain-free population. Eur $J$ Pain. 2011;15:376-383.

13. Lautenbacher S, Kunz M, Strate P, Nielsen J, Arendt-Nielsen L. Age effects on pain thresholds, temporal summation and spatial summation of heat and pressure pain. Pain. $2005 ; 115: 410-418$.

14. Abizanda P, Navarro JL, García-Tomás MI, López-Jiménez E, Martínez-Sánchez E, Paterna G. Validity and usefulness of hand-held dynamometry for measuring muscle strength in community-dwelling older persons. Arch Gerontol Geriatr. 2012;54:21-27. 
15. Bohannon RW. Hand-grip dynamometry predicts future outcomes in aging adults. $J$ Geriatr Phys Ther. 2008;31:3-10.

16. Norman K, Stobäus N, Gonzalez MC, Schulzke JD, Pirlich M. Hand grip strength: outcome predictor and marker of nutritional status. Clin Nutr. 2011;30:135-142.

17. Landi F, Russo A, Liperoti R, Danese P, Maiorana E, Pahor M, Bernabei R, Onder G. Daily pain and functional decline among old-old adults living in the community: results from the ilSIRENTE Study. J Pain Symptom Manage. 2009;38:350-357.

18. Von Elm E, Altman DG, Egger M, Pocock SJ, Gotzsche PC, Vandenbroucke JP. The Strengthening the Reporting of Observational Studies in Epidemiology (STROBE) Statement: guidelines for reporting observational studies. Ann Intern Med 2007; 147:573577.

19. Mitchell C, Adebajo A, Hay E, Carr A. Shoulder pain: diagnosis and management in primary care. Clinical review. BMJ. 2005;331:1124-1128.

20. Myburgh C, Lauridsen HH, Larsen AH, Hartvigsen J. Standardized manual palpation of myofascial trigger points in relation to neck/shoulder pain; the influence of clinical experience on inter-examiner reproducibility. Man Ther. 2011;16:136-140.

21. Taylor LJ , Harris J , Epps C , Herr K. Psychometric evaluation of selected pain intensity scales for use in cognitively impaired and cognitively intact older adults. Rehabil Nurs. $2005 ; 30: 55-61$.

22. Koo TK, Guo J, Brown CM. Test-retest reliability, repeatability, and sensitivity of an automated deformation-controlled indentation on pressure pain threshold measurement. $J$ Man Manip Ther. 2013;36:84-90. 
371 23. Fisher A. Algometry in diagnosis of musculoskeletal pain and evaluation of treatment

372

373

374

375

376

377

378

379

380

381

382

383

384

385

386

387

388

389

390

391

392

393 outcome: An update. J Musculoskelet Pain. 1998;6:5-32.

24. Park G, Kim CD, Park SB, Kim MJ, Jang SH. Reliability and usefulness of the pressure pain threshold measurement in patients with myofascial pain. Ann Rehabil Med. $2011 ; 35: 412-417$

25. Lobo CC, Marín AG, Sanz DR, López DL, López PP, Morales CR, Corbalán IS. Ultrasound evaluation of intrinsic plantar muscles and fascia in hallux valgus: A casecontrol study. Medicine (Baltimore). 2016;95(45):e5243.

26. Lobo CC, Morales CR, Sanz DR, Corbalán IS, Marín AG, López DL. Ultrasonography comparison of peroneus muscle cross-sectional area in subjects with or without lateral ankle sprains. J Manipulative Physiol Ther. 2016;39(9):635-644.

27. Hoch MC, Farwell KE, Gaven SL, Weinhandl JT. Weight-bearing dorsiflexion range of motion and landing biomechanics in individuals with chronic ankle instability. $J$ Athl Train. 2015;50:833-839.

28. Bland JM, Altman DG. Statistical methods for assessing agreement between two methods of clinical measurement. Int J Nurs Stud. 2010;47:931-936.

29. Stratford PW, Goldsmith C. Use of the standard error as a reliability index of interest: an applied example using elbow flexor strength data. Phys Ther. 1977;77:745-750.

30. Fernández-Carnero J, Fernández-de-Las-Peñas C, de la Llave-Rincón AI, Ge HY, Arendt-Nielsen L. Prevalence of and referred pain from myofascial trigger points in the forearm muscles in patients with lateral epicondylalgia. Clin J Pain 2007;23:353-360.

31. Cole LJ, Farrell MJ, Gibson SJ, Egan GF. Age-related differences in pain sensitivity and regional brain activity evoked by noxious pressure. Neurobiol Aging. 2010;31:494-503. 
394

395

396

397

398

399

400

401

402

403

404

405

406

407

408

409

410

411

412

413

414
32. Dhara PC, De S, Pal A, Sengupta P, Roy S. Assessment of hand grip strength of orthopedically challenged persons affected with upper extremity. J Life Sci. 2009; 1:121127.

33. Cuesta-Vargas A, Hilgenkamp T. Reference Values of Grip Strength Measured with a Jamar Dynamometer in 1526 Adults with Intellectual Disabilities and Compared to Adults without Intellectual Disability. PLoS One 2015;10:e0129585.

34. Roberts HC, Denison HJ, Martin HJ, Patel HP, Syddall H, Cooper C, Sayer AA. A review of the measurement of grip strength in clinical and epidemiological studies: towards a standardised approach. Age Ageing 2011;40:423-429.

35. Chung AS, Copay A, Olmscheid N, Campbell D, Walker B, Chutkan N. (2016) Minimum clinically important difference: current trends in the spine literature. Spine (Phila Pa 1976), http:// 10.1097/BRS.0000000000001990.

36. Zhou S, Kemp J, Després O, Pebayle T, Dufour A. The association between inhibition and pain tolerance in the elderly: evidence from event-related potentials. Eur J Pain 2015;19:669-676.

37. Ge HY, Fernández-de-las-Peñas C, Arendt-Nielsen L. Sympathetic facilitation of hyperalgesia evoked from myofascial tender and trigger points in patients with unilateral shoulder pain. Clin Neurophysiol. 2006;117:1545-1550.

38. Bohannon RW, Magasi S. Identification of dynapenia in older adults through the use of grip strength t-scores. Muscle Nerve. 2015;51:102-105. 


\section{Table 1 (on next page)}

Sociodemographic and pain intensity characteristics of the sample 
Table 1. Sociodemographic and pain intensity characteristics of the sample.

\begin{tabular}{|c|c|c|c|c|c|}
\hline \multicolumn{2}{|c|}{$\begin{array}{l}\text { Sociodemographic data and } \\
\text { pain intensity characteristics }\end{array}$} & \multirow{2}{*}{$\begin{array}{c}\begin{array}{c}\text { Total } \\
\text { sample } \\
(\mathrm{n}=132)\end{array} \\
75.54(6.86)\end{array}$} & \multirow{2}{*}{$\begin{array}{c}\begin{array}{c}\text { Painful } \\
\text { shoulders } \\
(\mathrm{n}=66)\end{array} \\
76.04(7.58)\end{array}$} & \multirow{2}{*}{$\begin{array}{c}\begin{array}{c}\text { Non-painful } \\
\text { shoulders } \\
(\mathrm{n}=66)\end{array} \\
75.05(6.26)\end{array}$} & \multirow{2}{*}{$\begin{array}{c}P-\text { value } \\
\text { case vs. } \\
\text { control } \\
.415^{*}\end{array}$} \\
\hline $\begin{array}{c}\text { Age } \\
\text { mean (SD) }\end{array}$ & $\geq 65$ years & & & & \\
\hline \multirow{3}{*}{$\begin{array}{c}\text { Age } \\
\text { distribution } \\
\mathrm{n}(\%)\end{array}$} & $65-70$ years & $34(25.8)$ & $18(27.3)$ & $16(24.2)$ & \multirow{3}{*}{$.783 \dagger$} \\
\hline & $71-80$ years & $60(45.5)$ & $28(42.4)$ & $32(48.5)$ & \\
\hline & $>80$ years & $38(28.8)$ & $20(30.3)$ & $18(27.3)$ & \\
\hline \multirow{2}{*}{$\begin{array}{l}\text { Sex } \\
\mathrm{n}(\%)\end{array}$} & Men & $51(38.6)$ & $23(34.8)$ & $28(42.4)$ & \multirow{2}{*}{$.475 \ddagger$} \\
\hline & Women & $81(61.4 \%)$ & $43(65.2)$ & $38(57.6)$ & \\
\hline \multirow{5}{*}{$\begin{array}{c}\text { Pain } \\
\text { intensity } \\
\text { mean (SD) }\end{array}$} & $65-70$ years & N/A & $4.94(1.80)$ & N/A & \multirow{3}{*}{ N/A } \\
\hline & $71-80$ years & N/A & $4.93(1.58)$ & N/A & \\
\hline & $>80$ years & N/A & $4.80(1.85)$ & N/A & \\
\hline & Men & N/A & $4.48(1.62)$ & N/A & \multirow{2}{*}{ N/A } \\
\hline & Women & N/A & $5.12(1.72)$ & N/A & \\
\hline
\end{tabular}


Table 2 (on next page)

Univariate correlation of the case-control groups and total sample 
Table 2. Univariate correlation of the case-control groups and total sample.

\begin{tabular}{|c|c|c|c|c|}
\hline \multicolumn{2}{|c|}{ Pearson's $(r)$ coefficient* } & \multirow{2}{*}{$\begin{array}{c}\text { Total } \\
\text { sample } \\
(\mathrm{n}=132)\end{array}$} & \multirow{2}{*}{$\begin{array}{c}\begin{array}{c}\text { Painful } \\
\text { shoulders } \\
(\mathrm{n}=66)\end{array} \\
-0.021\end{array}$} & \multirow{2}{*}{$\begin{array}{c}\begin{array}{c}\text { Non-painful } \\
\text { shoulders } \\
(\mathrm{n}=66)\end{array} \\
0.037\end{array}$} \\
\hline & Anterior deltoid PPT & & & \\
\hline \multirow{4}{*}{ Age } & ECRB PPT & -0.009 & 0.015 & 0.170 \\
\hline & Grip strength & $-0.327 \dagger$ & $-0.488 \dagger$ & -0.083 \\
\hline & Pain intensity & N/A & -0.003 & N/A \\
\hline & ECRB PPT & $0.806 \dagger$ & $0.590 \dagger$ & $0.677 \dagger$ \\
\hline \multirow{2}{*}{$\begin{array}{c}\text { Anterior } \\
\text { deltoid PPT }\end{array}$} & Grip strength & $0.315 \dagger$ & 0.161 & $0.372 \ddagger$ \\
\hline & Pain intensity & $\mathrm{N} / \mathrm{A}$ & -0.144 & $\mathrm{~N} / \mathrm{A}$ \\
\hline \multirow{2}{*}{ ECRB PPT } & Grip strength & $0.303 \dagger$ & 0.151 & $0.442 \dagger$ \\
\hline & Pain intensity & N/A & -0.146 & N/A \\
\hline Grip strength & Pain intensity & N/A & -0.109 & N/A \\
\hline \multicolumn{5}{|c|}{$\begin{array}{l}\text { Abbreviations: } \mathrm{ECRB}=\text { extensor carpi radialis brevis; } \mathrm{PPT}=\text { pressure pain threshold; N/A }=\text { Not } \\
\text { applicable. } \\
* \text { Correlations were interpreted as weak }(0.00-0.40) \text {, moderate }(0.41-0.69) \text { or strong }(0.70-1.00) \text { [19]. } \\
\dagger P<0.001 \\
+P=0.002\end{array}$} \\
\hline
\end{tabular}




\section{Table 3(on next page)}

Multivariate predictive analysis of the grip strength, anterior deltoid and ECRB PPT

Table 3. Multivariate predictive analysis of the grip strength, anterior deltoid and ECRB PPT. 
Table 3. Multivariate predictive analysis of the grip strength, anterior deltoid and ECRB PPT.

\begin{tabular}{clrl}
\hline Parameter & Model & $R^{2}$ change & Model $R^{2}$ \\
\hline PPT $\left(\mathrm{kg} / \mathrm{cm}^{2}\right)$ & & & \\
Anterior deltoid & 3.973 & & \\
& $-1.138 *$ group & $0.473^{\dagger}$ & \\
& $-0.493 *$ sex & $0.078^{\dagger}$ & 0.551 \\
& & & \\
ECRB & 3.559 & & \\
& $-1.129 *$ group & $0.565^{\dagger}$ & \\
& $-0.348 *$ sex & $0.048^{\dagger}$ & 0.614
\end{tabular}

Grip Strength (kg)

$\begin{array}{lll}69.079 & & \\ -15.070 * \text { sex } & 0.519^{\dagger} & \\ -0.477 * \text { age } & 0.108^{\dagger} & \\ -2.228 * \text { group } & 0.012^{\ddagger} & 0.638\end{array}$

Abbreviations: $\mathrm{ECRB}=$ extensor carpi radialis brevis; $\mathrm{PPT}=$ pressure pain threshold.

*Multiplay: age (years); sex $($ male $=0$; female $=1)$; group $($ control $=0$; case $=1)$.

$\dagger P$ value $<0.001$

$\$ P$ value $=0.045$ 


\section{Table 4(on next page)}

Intraexaminer reliability for the latent MTrP localization

Table 4. Intraexaminer reliability for the latent MTrP localization. 
Table 4. Intraexaminer reliability for the latent MTrP localization.

\begin{tabular}{|c|c|c|}
\hline $\begin{array}{l}\text { Intraexaminer } \\
\text { reliability }\end{array}$ & $\begin{array}{l}\text { Anterior deltoid } \\
\text { latent MTrP }\end{array}$ & $\begin{array}{c}\text { ECRB } \\
\text { latent MTrP }\end{array}$ \\
\hline $\begin{array}{l}\text { Repeated measures } \\
\text { ANOVA } P \text {-value }\end{array}$ & .114 & .646 \\
\hline $\begin{array}{l}\text { Cronbach's } \\
\text { alpha }\end{array}$ & 0.994 & 0.990 \\
\hline ICC A* (CI 95\%) & $0.98(0.978-0.994)$ & $0.98(0.963-0.989)$ \\
\hline$P$-value & $P<.001$ & $P<.001$ \\
\hline $\mathrm{ICC}^{\dagger}(\mathrm{CI} 95 \%)$ & $0.98(0.978-0.994)$ & $0.98(0.963-0.989)$ \\
\hline$P$-value & $P<.001$ & $P<.001$ \\
\hline $\mathrm{SEM}(\mathrm{cm})$ & 0.122 & 0.118 \\
\hline $\begin{array}{c}\operatorname{MDC} \ddagger(\mathrm{cm}) \\
(\mathrm{CI} 95,90,80 \%)\end{array}$ & $0.338 / 0.284 / 0.221$ & $0.327 / 0.275 / 0.214$ \\
\hline Kendall tau_b $(\tau \mathrm{B})$ & -0.101 & -0.037 \\
\hline$P$-value & $P=.360$ & $P=.735$ \\
\hline$R^{2}$ & 0.056 & 0.005 \\
\hline$P$-value & $P=.131$ & $P=.669$ \\
\hline
\end{tabular}




\begin{abstract}
Abbreviations: $\mathrm{ANOVA}=$ Analysis of variance $\mathrm{CI}=$ Confidence interval; $\mathrm{ECRB}=$ extensor carpi radialis brevis; ICC $=$ Intraclass correlation coefficient; $\mathrm{MDC}=$ Minimum detectable change; $\mathrm{MTrP}=$ Myofascial trigger point; $\mathrm{PPT}=$ pressure pain threshold; SEM $=$ Standard error of measurement.

*ICC A was calculated by means of a two-factor model with mixed effects.

ICC B was performed by means of one-factor model with random effects.

¥MDC was determined for each CI: $\sqrt{2} \times 1.96 \times s w(95 \% \mathrm{CI}) ; \sqrt{2} \times 1.645 \times s w(90 \%$ CI); $\sqrt{ } \sqrt{2} \times 1.28 \times s w(80 \% \mathrm{CI})$.
\end{abstract}

1 
Figure 1

Box plots to illustrate anterior deltoid PPT values between shoulders with and without pain..

Figure 1. Box plots to illustrate anterior deltoid PPT values between shoulders with and without pain. Abbreviations: MCID = minimal clinically important differences; PPT = pressure pain threshold.

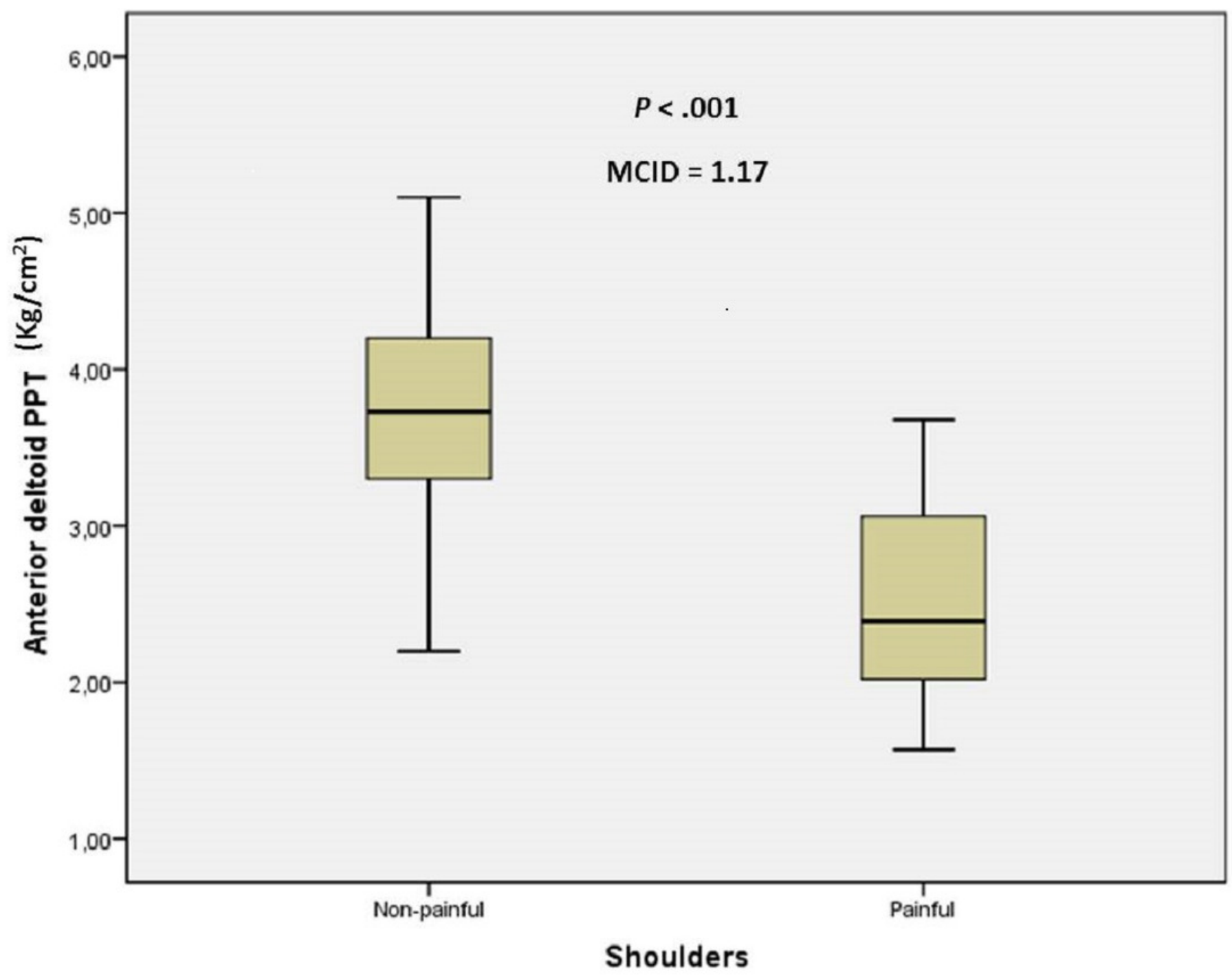


Figure 2

Box plots to illustrate ECRB PPT values between shoulders with and without pain

Figure 2. Box plots to illustrate ECRB PPT values between shoulders with and without pain. Abbreviations: $\mathrm{ECRB}=$ extensor carpi radialis brevis; $\mathrm{MCID}=$ minimal clinically important differences; PPT = pressure pain threshold.

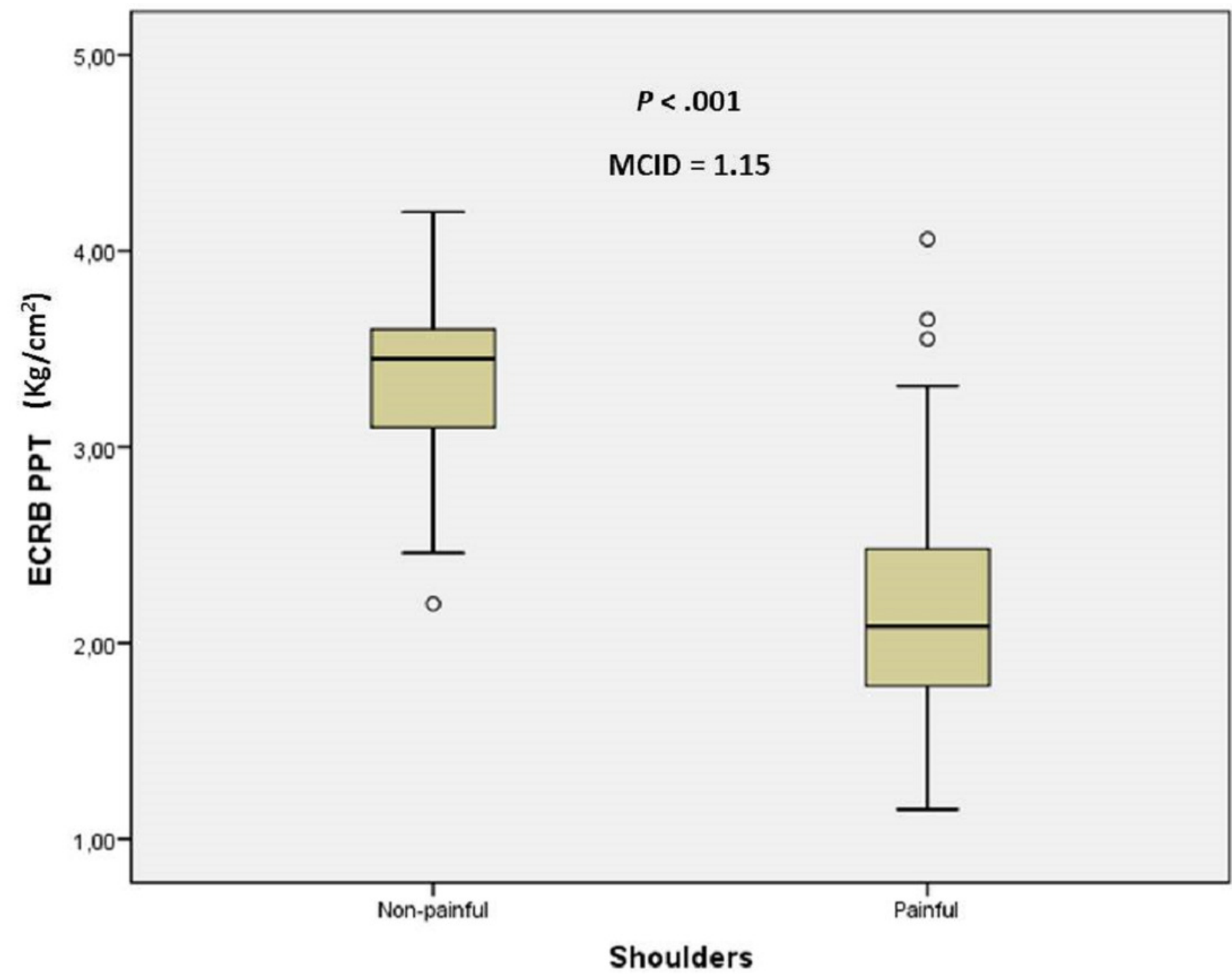


Figure 3

Box plots to illustrate grip strength values between shoulders with and without pain

Figure 3. Box plots to illustrate grip strength values between shoulders with and without pain. Abbreviations: $M C I D=$ minimal clinically important differences.

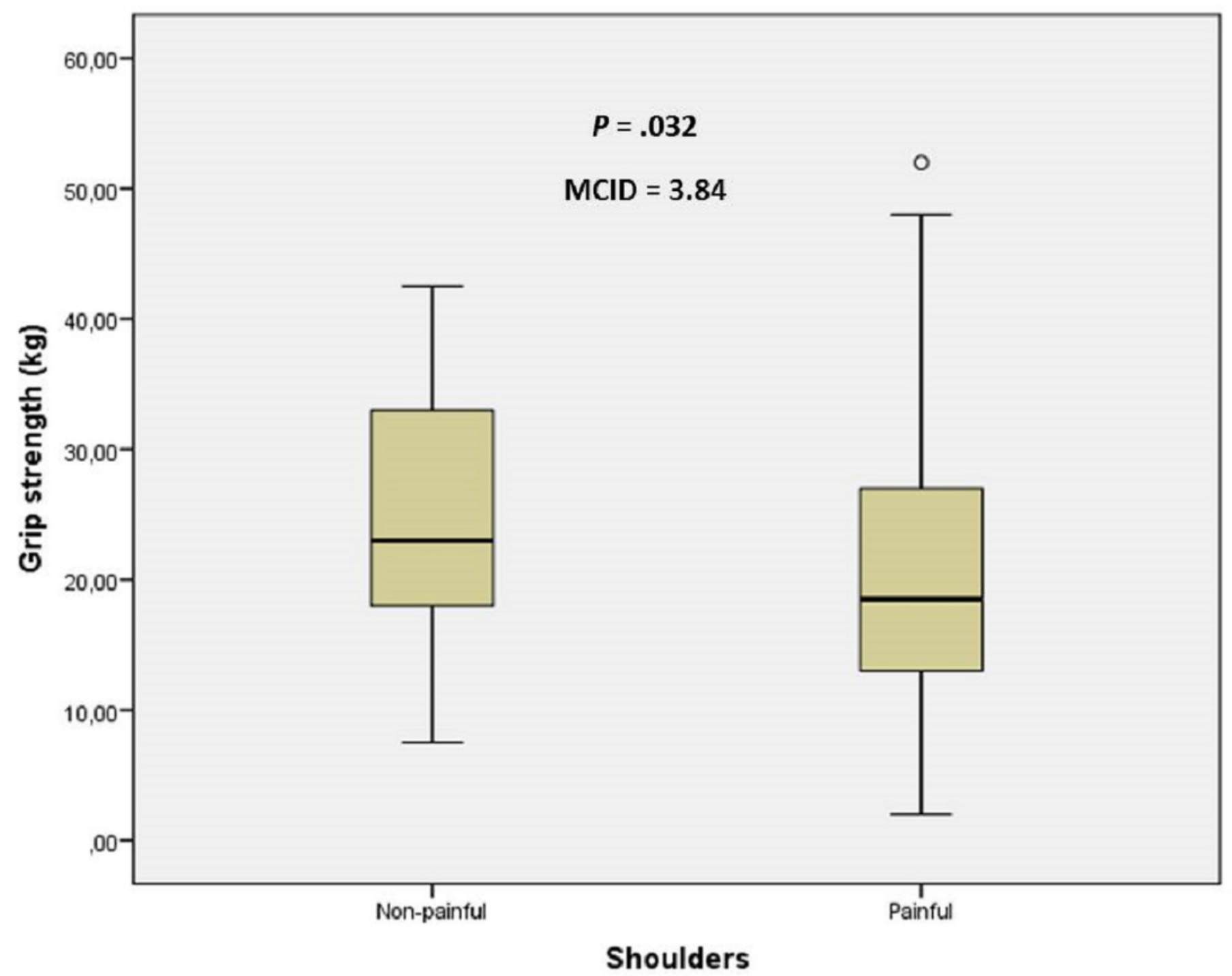


Figure 4

Regression tree nodes to predict the grip strength, anterior deltoid and ECRB PPT
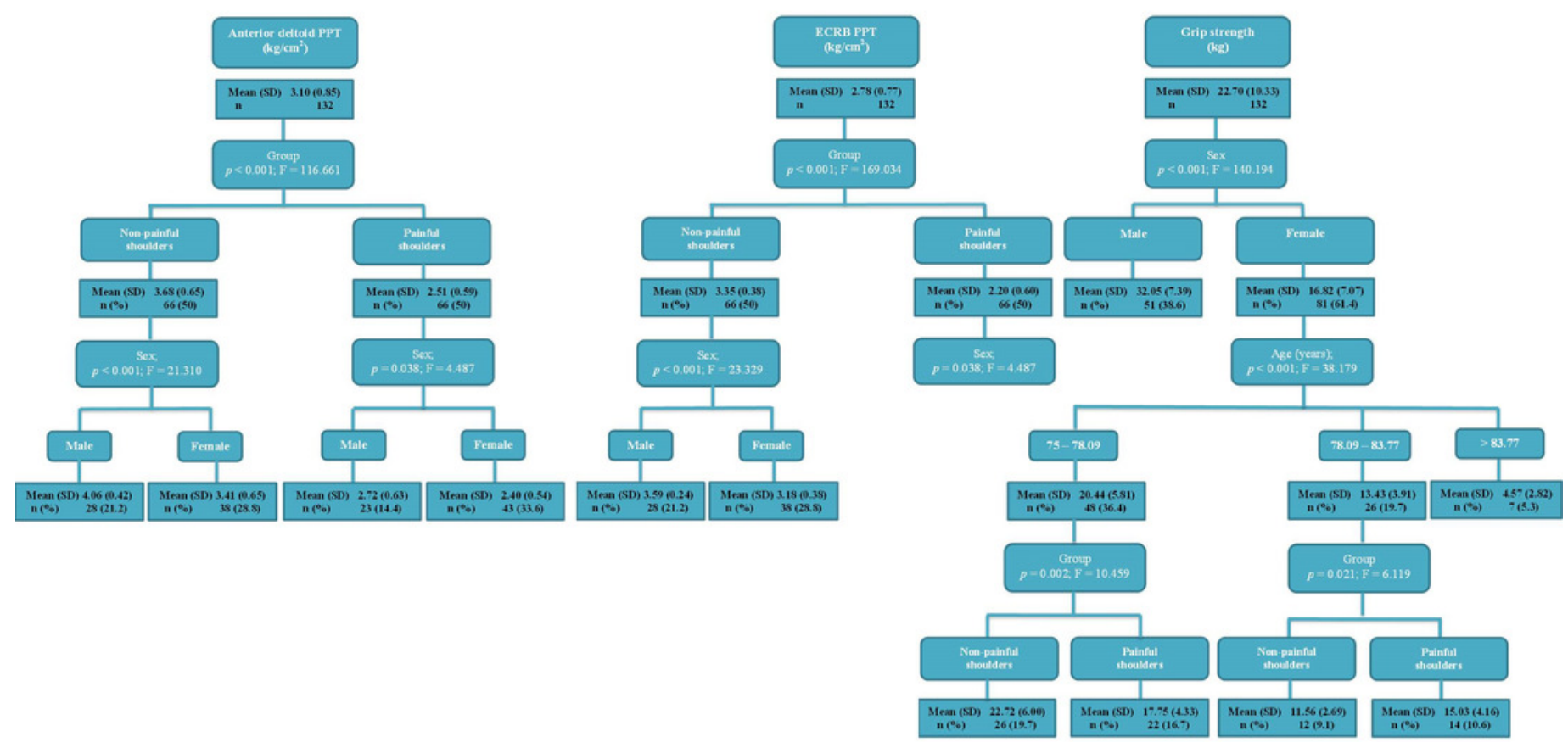
Figure 5

Bland and Altman ${ }^{2}$ graphs, completed with linear regression analysis, of the intraexaminer reliability of the anterior deltoid $(A)$ and ECRB $(B)$ latent MTrPs localization procedure.

Figure 5. Bland and Altman² graphs, completed with linear regression analysis, of the intraexaminer reliability of the anterior deltoid (A) and ECRB (B) latent MTrPs localization procedure. Abbreviations: $\mathrm{ECRB}=$ extensor carpi radialis brevis; MTrPs = myofascial trigger points.
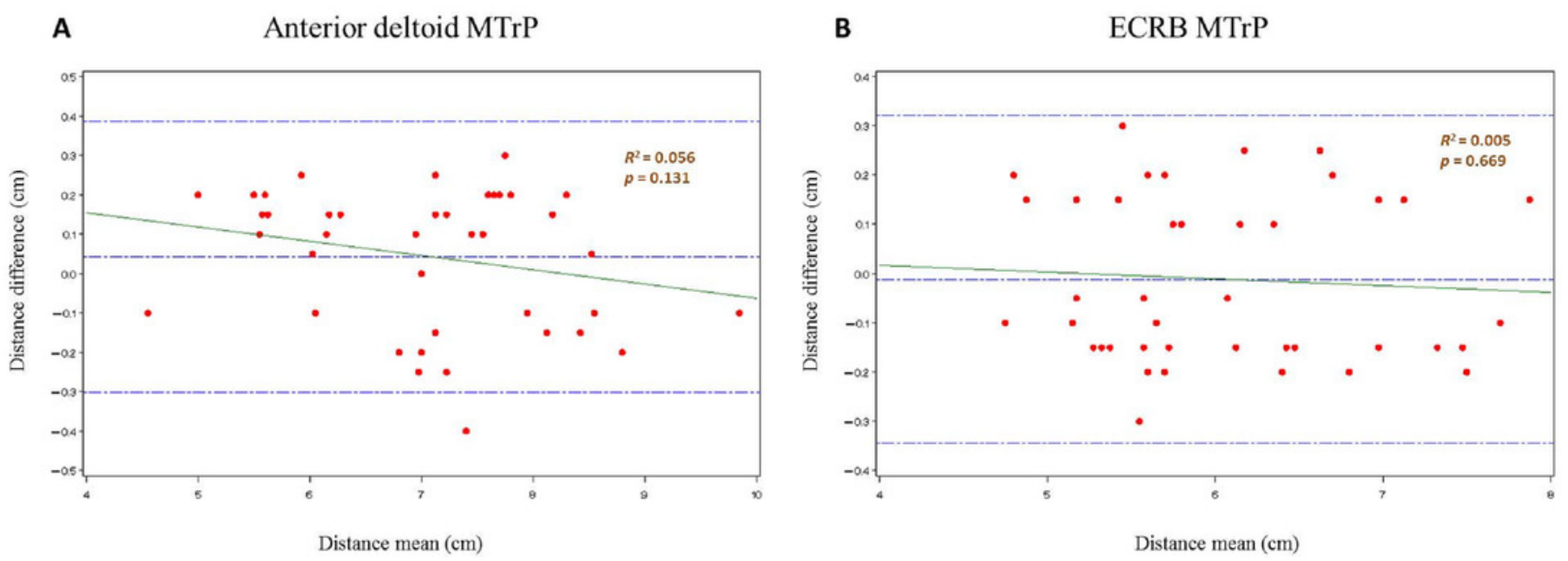